\title{
Rituximab therapy in Greek patients with rheumatoid arthritis
}

\author{
Aristotelis P Tsiakalos* \\ Nestor K Avgoustidis* \\ Haralampos M Moutsopoulos \\ Department of Pathophysiology, \\ Medical School, National Univercity \\ of Athens, Athens, Greece. "These \\ authors contributed equally \\ to this work
}

Objective: An open-label, prospective, uncontrolled study created to investigate clinical response, serological changes and side effects in Greek patients with rheumatoid arthritis (RA), after B-cell depletion with rituximab.

Methods: Patients with high disease activity (disease activity score [DAS]-28 $>5.1$ ) were selected for treatment with rituximab and received two infusions, 1 gr each, 2 weeks apart. Different disease parameters (visual analog scale, DAS-28, C-reactive protein [CRP], erythrocyte sedimentation rate, health assessment questionnaire, complement (C3), C4, rheumatoid factor [RF], anti-cyclic citrullinated peptide antibody [anti-CCP], swollen joint count, tender joint count, immunoglobulin $\mathrm{M}$ [IgM], $\operatorname{IgG}, \operatorname{IgA}$ ) were performed at base line, 2, 4, and 6 months post-treatment. Response was defined according to the American College of Rheumatology (ACR) criteria.

Results: Seventeen patients received therapy. Treatment led to a reduction in various disease parameters. ACR20 was achieved in $41.11 \%$ of patients by week $8,52.94 \%$ by week 16 , and $82.35 \%$ by week 24 . ACR50 was achieved in $5.88 \%$ by week $8,41.17 \%$ by week 16 , and $64.7 \%$ by week 24 . ACR70 was achieved only by week 24 in $23.52 \%$ of patients. Statistical analysis has shown no differences in clinical response, between RF positive/negative patients, and anti-CCP-positive/negative patients, while decline of RF was better correlated with reduction of DAS-28 than with anti-CCP.

Conclusions: Rituximab is a well tolerated and effective treatment in RA. Response was not correlated to RF or anti-CCP positivity. Decline of RF was associated with clinical response and reduction of DAS-28 and CRP.

Keywords: rituximab, Greek patients, rheumatoid arthritis

\section{Introduction}

Rheumatoid arthritis (RA) is a chronic systemic autoimmune disease that is estimated to affect $1 \%$ of the population worldwide, including all ethnic groups. The female/ male ratio is 3:1 (Sangha 2001; Lawrence and Haynes 2002; Lawrence et al 1998). It is characterized by symmetrical joint inflammation, morning stiffness, and causes cartilage damage, bone erosions and deformity (Pincus et al 1984).

Rheumatoid arthritis is considered to be a nonorgan-specific autoimmune disease in which genetic, hormonal, immunologic and environmental factors play a role. Greek and North European RA patients have differences. Greek patients have less inflammatory articular disease, fewer extra-articular manifestations, less severe joint damage, and a high frequency of Ro(SSA) antibodies linked to a higher prevalence of secondary Sjögren syndrome (Drosos and Moutsopoulos 1995; Drosos et al 1992). Furthermore, Greek RA patients are characterized with a lack of association with human leukocyte antigens (HLA) and only a weak association with HLA-DR1 and DR4 antigens (Boki et al 1992, 1993).

Over the last three decades there has been significant improvement in patient outcomes. Even with advances in disease management, a population of patients with 
refractory RA exists. In the clinical trials that led to approval of anti-tumor necrosis factor (TNF), 25\%-40\% of patients failed to achieve American College of Rheumatology (ACR)-20 (Keystone et al 2004; Lipsky et al 2000; Weinblatt et al 2003; Feltelius et al 2005). Furthermore, a proportion of patients experience treatment-limiting-side effects, and 30\%-40\% of patients who respond to anti-TNF continue to experience residual level of disease activity (Conen et al 2006).

The need for treatment beyond TNF inhibitors in RA has become clear and rituximab is one such novel therapy. Rituximab is a genetically engineered chimerical monoclonal antibody, which binds to the antigen CD20, which regulates cell cycle initiation and differentiation. CD20 is found in normal and malignant pre-B, and mature B-lymphocytes. The antigen is absent in hematopoietic stem cells and plasma cells (Hoffman-La Roche 2000). B-cells are believed to play a role in the pathogenesis of RA and are associated to chronic synovitis (Benoist and Mathis 2000; Panagyi 2005). Edward and Cambridge (Edwards and Cambridge 2001) introduced the concept of human auto antibody-associated disease and 'self-perpetuating' auto reactive B-cells. On the basis of this hypothesis, the first published trials of rituximab in RA were set up and carried out at University College, London, UK (Edwards et al 1999). Benefit was confirmed by De Vita and colleagues (2002) and then further established in a large randomized trial (Edwards et al 2004).

\section{Patients and methods}

This is an open-label, clinical, observational, uncontrolled study which included seventeen Greek patients with refractory RA. All patients satisfied the ACR diagnostic criteria for RA (Arnett et al 1988). The criterion for high disease activity that patients had to fulfill in order to enter the study was the DAS-28 score which should be more than 5.1. Two patients were male and 15 were female. The median age was 53 years (range 27-78), and the median disease duration was 6 years (range 1-23). RF positive (positive : $>20 \mathrm{IU} / \mathrm{L}$ ) were $76 \%$, and anti-cyclic citrullinated peptide antibody (anti-CCP) positive (positive: $>15 \mathrm{IU} / \mathrm{L}$ ) were $65 \%$. The median number of pretreatment disease-modifying antirheumatic drugs (DMARDS) was three, the median number of pre-treatment biological factors was two and the mean/SD value of DAS-28 score was $6.6 \pm 0.78$. The study was approved by the hospital ethics review board. Written consent was obtained from all patients.

\section{Statistical analysis}

A Student's t-test was applied for comparison of the normalized values. A P value $<0.05$ was considered significant.
The DAS28, health assessment questionnaire (HAQ) 20, C-reactive protein (CRP), and erythrocyte sedimentation rate (ESR) differences were calculated and the Mann-Whitney U test was used to compare them between rheumatioid factor (RF) $(-) / \mathrm{RF}(+)$ patients, and anti-CCP (-)/anti-CCP (+) patients.

\section{Treatment}

Patients continued their baseline DMARD treatment and other concomitant medications with no changes during follow-up of 24 weeks. Rituximab was administrated as an intravenous infusion of two dosages, $1000 \mathrm{mg}$ each, with 2 weeks apart. Prior to each infusion, patients received paracetamol $600 \mathrm{mg}$ (IV), Dimetindene (IV) and methylprednilosone $125 \mathrm{mg}$ (IV) to attenuate possible infusion-related symptoms.

During infusions patients were closely observed for infusion related symptoms. However, there were no such symptoms necessitating divergence from the above schedule. No further rituximab infusions were administrated during the subsequent follow up period.

\section{Clinical assessments}

At start point a thorough history and physical examination was conducted and recorded, together with baseline demographic data.

For each patient at baseline and at weeks 8,16 , and 24 the number of tender and swollen joints (total number: 28), visual analogue scale (VAS) and the DAS-28, HAQ-20 scores were recorded. Blood samples were obtained at baseline and at follow-up visits for assessment of laboratory measures including ESR, CRP, complement (C3) and C4 levels, immunoglobulin (Ig) A, IgM, and IgG levels, RF, and anti-CCP antibodies. Samples were processed and analyzed using standard techniques

\section{Results}

The baseline characteristics of the cohort are outlined in Table 1.

Table I Baseline characteristics

\begin{tabular}{ll}
\hline Total Number of patients & 17 \\
Male/Female & $2 / 15$ \\
Age (yrs): median (range) & $53(27-78)$ \\
Disease duration: median (range) & $6(1-23)$ \\
RF positive n\% & $13(76)$ \\
CCP positive $\mathrm{n} \%$ & $1 \mathrm{I}(65)$ \\
Number of pre-treatment DMARDs: median (range) & $3(2-5)$ \\
Number of pre-treatment biological: median (range) & $2(1-3)$ \\
Prednisolone therapy: $n$ (\%) & $14(82)$ \\
Prednisolone dosage: median (range) & $7,5(2,5-15)$ \\
\hline
\end{tabular}


Our patients had multi-DMARD and biologic-resistant RA. Apart from one patient with advanced pulmonary fibrosis, none of the others had any major extra-articular disease. Follow up data were available at all 17 patients at 2, 4, and 6 months. Changes in various parameters during follow up are shown in Table 2.

Fourteen patients presented clinical improvement as measured by the ACR criteria (Figure 1). Rituximab was effective in suppressing disease activity as evidenced by a statistical significant reduction in DAS-28 and HAQ-20 scores in 6 months follow up (Figure 2). Major improvements were also seen in various parameters of the disease including CRP and ESR.

Primary outcome measure for this study was efficacy as determined by ACR score. Secondary outcome measures were: DAS-28 and HAQ-20 scores and serological changes as determined by RF, anti-CCP, CRP, ESR. Auto antibodies levels decreased after rituximab therapy (Figure 3). RF levels revealed a statistically significant decrease between the start point and 8th $(\mathrm{p}<0.01), 16$ th $(\mathrm{p}<0.01)$ and 24th $(\mathrm{p}<0.001)$ week. On the contrary, the differences of the anti-CCP values were not statistically significant (week 8 [p $<0.1$, week 16 [p $<0.1$ ], week 24 [p $<0.1]$.

Total serum Igs decreased moderately during follow up. Their mean values remained within normal levels (Figure 4).

The DAS28, HAQ 20, CRP, and ESR differences between week 0 (start point) and weeks 8,16 , and 24, were compared for the RF (-) and RF (+) patients, and anti-CCP $(-)$ and anti-CCP (+) patients. There were no significant statistical differences in clinical response between these groups of patients.

Rituximab was well tolerated by all patients. There were no major adverse events during infusions, and no serious infections were observed in post-infusion period of six months. Concerning the minor side effects during the infusions we observed fever and chills in two patients and migraine in one; in the post-treatment period two patients experienced upper respiratory tract infections and another one tiredness and weakness.

\section{Discussion}

The results of this open label study showed substantial and persistent clinical benefit in patients with resistant RA who have had inadequate response to multiple DMARD and biological treatment.

The responses seen in this open label study support the hypothesis that B cells are key contributors to the immunopathogenesis of RA through several potential mechanisms (Kim and Berek 2000; Gause and Berek 2004; Reparon-Schuijt et al 2001; Takemura et al 2001; Zhang and Bridges 2001; Shiokawa et al 2003). In our study the patients who were RF and anti-CCP seronegative demonstrated a similar treatment effect as those who were RF (+) and anti$\mathrm{CCP}(+)$ further suggesting that rituximab may act through several different pathways relevant to pathogenesis of

Table 2 Mean \pm SD values of various parameters with rituximab treatment

\begin{tabular}{|c|c|c|c|c|}
\hline $\begin{array}{l}\text { Mean/SD values } \\
\text { of various parameters }\end{array}$ & Baseline & Week 8 & Week 16 & Week 24 \\
\hline CRP mg/L & $48,7 \pm 49,5$ & $24,4^{* *} \pm 25,4$ & $14,9^{* *} \pm 14,7$ & $12,1^{* *} \pm 10,2$ \\
\hline $\mathrm{ESR} \mathrm{mm} / \mathrm{h}$ & $48, I \pm 27,2$ & $37,5^{\dagger} \pm 21,8$ & $25,8^{* *} \pm 12,7$ & $23,8^{* *} \pm 13,4$ \\
\hline $\mathrm{RF} \mathrm{IU} / \mathrm{ml}$ & $140 \pm 498,8$ & $61,8^{* k} \pm 469,73$ & $48,5^{* *} \pm 39,35$ & $4 I^{* *} \pm 40,5$ \\
\hline $\mathrm{CCP} \mathrm{U/ml}$ & $56 \pm 44,1$ & $49,8 \pm 40,5$ & $46,2 \pm 39,3$ & $42,2 \pm 40,5$ \\
\hline C3 mg/dl & $136,3 \pm 38,2$ & $128,2 \pm 33,18$ & $118,4 \pm 38,5$ & $121,7 \pm 28,8$ \\
\hline $\mathrm{C} 4 \mathrm{mg} / \mathrm{dl}$ & $24,4 \pm 10,1$ & $23, I \pm 8,6$ & $23 \pm 7,2$ & $22,5 \pm 6,8$ \\
\hline IgM mg/dl & $164,2 \pm 112,5$ & $139, \mid \pm 94,9$ & $116,4 \pm 98,4$ & $|12,4 \pm 55|$, \\
\hline $\lg \mathrm{A} \mathrm{mg} / \mathrm{dl}$ & $296, I \pm 155,2$ & $275 \pm 162,4$ & $243,2 \pm 119,1$ & $235,8 \pm 123,8$ \\
\hline lgG mg/dl & $|500,7 \pm 5| 3, \mid$ & $1249,2 \pm 353,5$ & $1159 \pm 311,2$ & $1153,5 \pm 286,3$ \\
\hline HAQ 20 & $2, I \pm 0,42$ & $1,6^{*} \pm 0,4 \mid$ & $1,2^{*} \pm 0,42$ & $\mathrm{I}, \mathrm{I}^{*} \pm 0,47$ \\
\hline DAS-28 & $6,6 \pm 0,78$ & $5,69^{* * *} \pm 0,98$ & $4,95^{*} \pm 0,98$ & $4,42^{*} \pm 1,12$ \\
\hline VAS & $82,8 \pm 11,5$ & $65,7^{*} \pm 17,4$ & $50,9^{*} \pm 14,4$ & $39,7^{*} \pm 14$ \\
\hline TJC & $18,2 \pm 7,2$ & $14,3^{\dagger} \pm 6,8$ & $10,8^{* *} \pm 6,3$ & $8,5^{*} \pm 6$ \\
\hline SJC & $9,7 \pm 2,8$ & $7,4^{\dagger} \pm 3,3$ & $5,6^{*} \pm 2,3$ & $4,6^{*} \pm 2,5$ \\
\hline
\end{tabular}

Notes: "P<0, 0001; " $\mathrm{P}<0,01$; ${ }^{\mathrm{P}}<0,05 ; \mathrm{P}=$ not significant. 


\section{$A C R$ response rates}

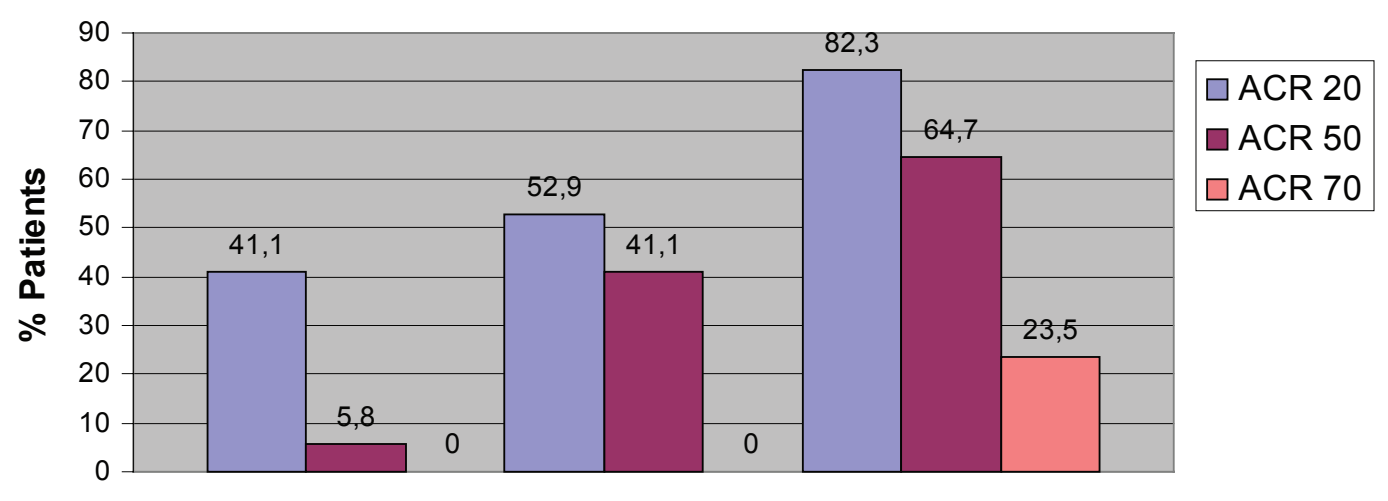

Week 8

Week 16

Week 24

Figure I ACR responses in patients with RA treated with rituximab.

DAS28 \& HAQ20 mean values over time

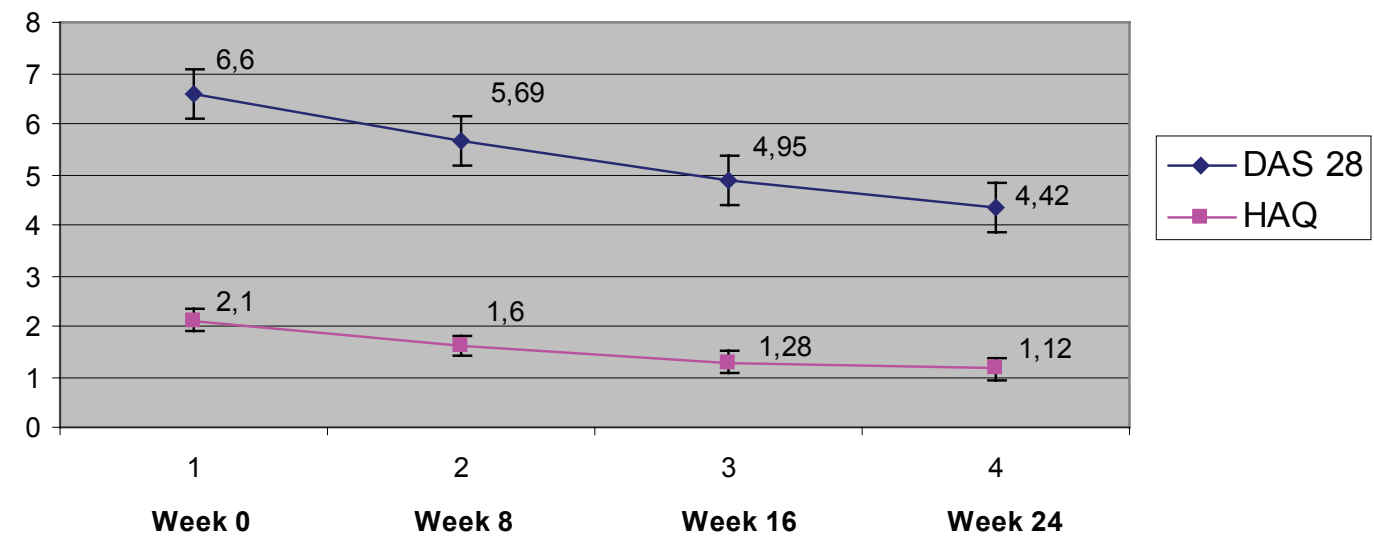

Figure 2 Reduction in DAS28 and HAQ20 after therapy with rituximab.

\section{RF \& CCP mean values over time}

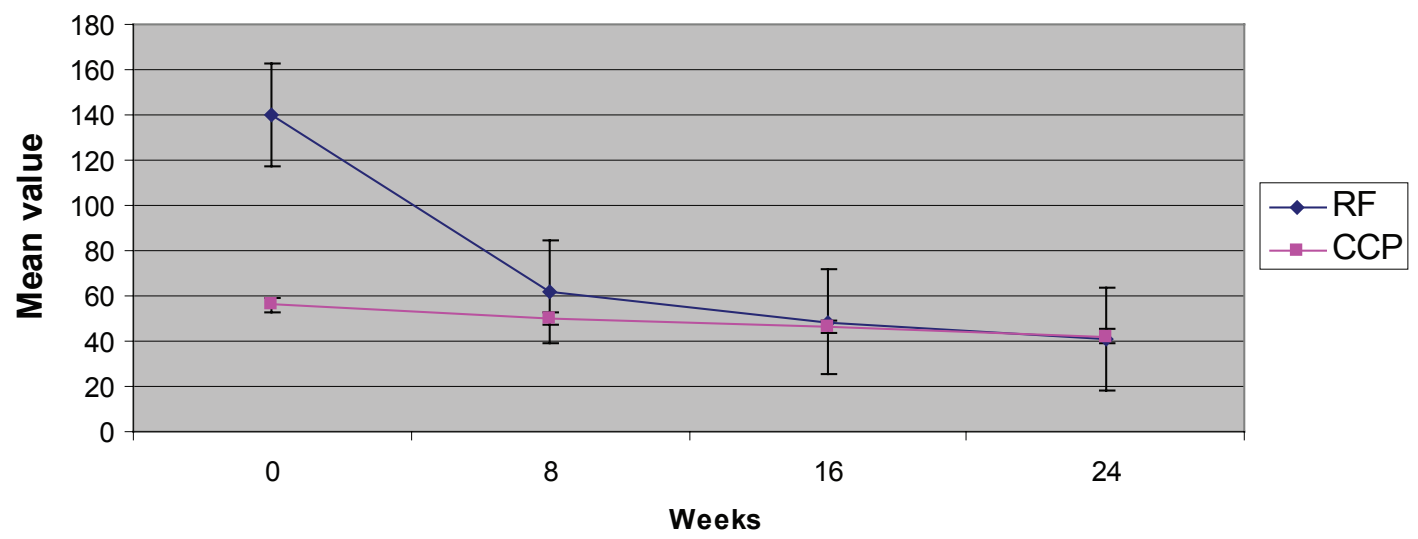

Figure 3 Reduction in RF and anti-CCP levels after rituximab treatment. 
$\lg M, \lg A, \& \lg G$ mean values over time

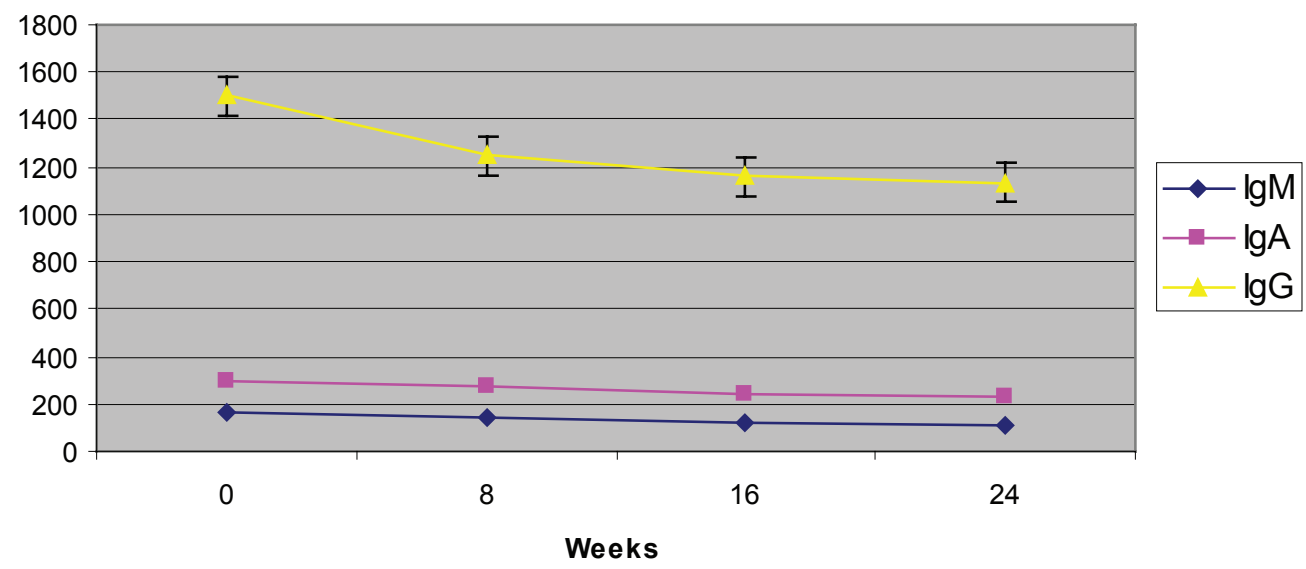

Figure 4 Immunoglobulin levels during rituximab therapy.

inflammatory arthritis. These pathways include production of auto antibodies such as RF and anti-CCP, T-cell activation, and production by macrophages proinflammatory cytokines (Dorner and Burmeister 2003; Tuscano et al 2003).

In our study, the auto-antibodies profile was different between RF and anti-CCP. RF decreased statistically significant and was correlated with the reduction of DAS-28 and CRP, while anti-CCP did not correlate with the reduction of DAS-28 and CRP as a measure of disease activity. This observation suggests that RF is a better indicator of patient's clinical and serological response after rituximab treatment than anti-CCP. As expected from the mechanism of rituximab action, treatment with this agent led to a rapid and complete depletion of CD20+ peripheral B cells. The CD20 antigen is not expressed on stem cells or plasma cells, so it is not surprising that the mean levels of $\operatorname{IgA}, \operatorname{IgM}$, and $\operatorname{IgG}$ generally remained within the normal range throughout the 24 weeks. The prolonged depletion of CD20+ peripheral B cells in rituximab-treated patients raises the question of whether these patients may have great risk for severe infections, although the data from this and other studies (Fleischmann et al 2006; Keystone et al 2006) do not support this hypothesis, and only four patients had minor upper respiratory tract infections during follow up for 24 weeks. In conclusion, our results demonstrate that a single course of two $1000 \mathrm{mg}$ infusion of rituximab given 2 weeks apart, in combination with baseline DMARDs, produced significant clinical and functional benefits at 24 weeks in patients with refractory RA in a real life setting outside from formal clinical trials.

Ongoing studies will continue to examine the long-term safety of rituximab in RA patients.

\section{Conclusions}

Treatment with rituximab was effective and well tolerated without major adverse events. Patient response to treatment was independent to the presence of RF and anti-CCP antibodies. The decline of RF was correlated with the reduction of disease activity (DAS-28 and CRP); on the contrary, the anti-CCP titer was not statistical significantly correlated to disease activity (DAS-28 and CRP). These observations suggest that RF is a better serological marker than anti-CCP for the evaluation of response to rituximab during follow-up.

\section{Disclosure}

The authors declare that they have no competing interests. Tsiakalos Aristotelis and Avgoustidis Nestor were involved in the conception, design, acquisition, analysis and interpretation of the study data. Moutsopoulos Haralampos created, drafted, and revised the manuscript.

\section{References}

Arnett FC, Edworthy SM, Blonch DA, et al. 1988. The American Rheumatism Association 1987 revised criteria for classification of rheumatoid arthritis. Arthritis Rheum, 31:315-24.

Benoist C and Mathis D. 2000. A revival of the B-cell paradigm for rheumatoid arthritis pathogenesis. Arthritis Res, 2:90-4.

Boki KA, Drosos AA, Tzioufas AG, Lanchbury JS, Panayi GS, Moutsopoulos HM, et al. 1993. Examination of HLA-DR4 as a severity marker for rheumatoid arthritis in Greek patients. Ann Rheum Dis, 52:517-9.

Boki KA, Panayi GS, Vaughan RW, Drosos AA, Moutsopoulos HM, Lanchbury JS, et al. 1992. HLA Class II sequence polymorphisms and susceptibility to RA in Greeks. Arthritis Rheum, 35:749-55.

Conen S, Emery P, Greenwald M, et al. 2006. Efficasy and safety of rituximab in active rheumatoid arthritis patients who experienced an inadequate response to one or more anti-TNF therapies (REFLEX study). Arthritis Rheum, 54:2793-806. 
De Vita S, Zaja F, Sacco S, De Candia A, Fanin R, Ferraccioli G, et al. 2002. Efficacy of selective B cell blockade in the treatment of rheumatoid arthritis: evidence for a pathogenic role of B-cells. Arthritis Rheum, 46:2029-33.

Dorner T and Burmeister GR. 2003. The role of B cells in rheumatoid arthritis: mechanisms and therapeutic targets. Curr Opin Rheumatol, 15:246-52.

Drosos AA, Lanchbury JS, Panayi GS, Moutsopoulos HM, et al. 1992. Rheumatoid arthritis in Greek and British patients, a comparative clinical, radiological and serologic study. Arthritis Rheum, 35:745-8.

Drosos AA and Moutsopoulos HM. 1995. Reumatoid arthritis in Greece: clinical, serological and genetic considerations. Clin Exp Rheumatol, 13(Suppl 12):S7-12.

Edwards JCW, Cambridge G, Abrahams VM, et al. 1999. Do selfperpetueting B lymphocytes drive human autoimmune disease? Immunology, 97:188-96.

Edwards JCW and Cambridge G. 2001. Sustained improvement on rheumatoid arthritis following a protocol designed to deplete B lympocytes. Rheumatology, 40:205-11.

Edwards JCW, Szczepanski L, Szechinski J, et al. 2004. Efficasy of B-cell targeted therapy with rituximab in patients with rheumatoid arthritis. $N$ Engl J Med, 350:2572-81.

Feltelius N, Fored CM, Blomqvist P, et al. 2005. Results from a nationwide postmarketing cohort study of patients in Sweden treated with etanercept. Ann Rheum Dis, 64:246-52.

Fleischmann, Van Vollenhoven R, Udell J, et al. 2006. Infusion-associated events decrease with repeat courses of rituximab in patients with active rheumatoid arthritis. Arthritis Rheum, 54(Suppl):S238.

Gause A, Berek C. Role of B-cells in the pathogenesis of rheumatoid arthritis:potential implication of treatment. Bio-Drugs, 2001;15:73-9.

Hoffman-La Roche. June 21, 2000. Rituxan product monograph. Mississauga, Ontario.

Keystone E, Fleischmann RM, Emery P, et al. 2006. Long-term efficacy and safety of a repeat treatment course of rituximab in RA patients with an inadequate response to one or more TNF inhibitors. Arthritis Rheum, (54 Suppl):S328.

Keystone EC, Schiff MH, Kremer JM, et al. 2004. Once-weekly administration of $50 \mathrm{mf}$ of etanrecept in patients with active RA: results of a multicenter, randomized, double-blind, placebo-controlled trial. Arthritis Rheum, 50:353-63.
Kim HJ and Berek C. 2000. B-cells in rheumatoid arthritis. Arthritis Res, $2: 126-31$

Lawrence JB and Haynes MK. 2002. Rheumatoid arthritis-a molecular understanding. Ann Intern Med, 136:908-22.

Lawrence RC, Helmick CG, Arnett FC, et al. 1998. Estimates of the prevalence of arthritis and selected musculoskeletal disorders in the United States. Arthritis Rheum, 41:778-9.

Lipsky PE, Van der Heijde DM, St Clair EW, et al. 2000. Infliximab and methotrexate in the treatment of rheumatoid arthritis. $N$ Engl J Med, 343:1594-602.

Panagyi GS. 2005. B-cells: a fundamental role in the pathogenesis of rheumatoid arthritis? Rheumatology (Oxford), 44(Suppl 2):ii3-ii7.

Pincus T, Callahan LF, Sale WG, et al. 1984. Severe functional declines, work disability, and increased mortality in seventy-five rheumatoid arthritis patients studied over nine years. Arthritis Rheum, 27:864-72.

Reparon-Schuijt CC, Van Esch WJ, Van Kooten C, et al. 2001. Presence of a population of $\mathrm{CD} 20+, \mathrm{CD} 38-\mathrm{B}$ lymphocytes with defective proliferative responsivness in the synovial compartment of patients with rheumatoid arthritis. Arthritis Rheum, 44:2029-37.

Sangha O. 2001. Epidemiology of rheumatic diseases. Rheumatology (Oxford), 39(Suppl):3-12.

Shiokawa S, Matsumoto N, Nishimura J, et al. 2003. Clonal analysis of $B$ cells in the synovial membrane of patients with rheumatoid arthritis. Scand J Rheumatol, 32:12-8.

Takemura S, Klimiuk PA, Braun A, et al. 2001. T-cell activation in rheumatoid synovium is B-cell dependent. J Immunol. 167:4710-8.

Tuscano JM, Harris GS, Tedder TF, et al. 2003. B lymphocytes contribute to autoimmune disease pathogenesis:current trends and clinical implications. Autoimmun Rev, 2:101-8.

Weinblatt ME, Keystone EC, Furst DE, et al. 2003. Adalimumab, a fully human anti-tumor necrosis factor alpha monoclonal antibody, for the treatment of rheumatoid arthritis in patients taking concomitant methotrexate: the ARMADA trial. Arthritis Rheum, 48:35-45.

Zhang Z and Bridges SL. 2001. Pathogenesis of rheumatoid arthritis. Role of B lymphocytes. Rheum Disease Clin North Am, 27:335-53. 